\title{
Household food insecurity and associated factors among households in Wolaita Sodo town, 2015
}

\author{
Abraham Tadesse Tantu', Tsegaye Demissie Gamebo ${ }^{2}$, Berhanu Kuma Sheno ${ }^{3}$ \\ and Mulugeta Yohannis Kabalo $2,4^{*}$
}

\begin{abstract}
Background: Culturally, food insecurity is expected in rural households. But it is considerable in urban setting due to many factors. Yet this has been hardly recognized in the study area. Therefore, this study intended to assess the level of household food insecurity and associated factors among households in Wolaita Sodo town, Southern Ethiopia, 2015.
\end{abstract}

Methods: A cross-sectional study was conducted in Wolaita Sodo town. Overall, 609 households were selected from the town by multistage sampling. Data were collected using pretested and structured tool through interviewing household heads. Household food insecurity access was assessed with Household Food Insecurity Access Scale questions. Data were analyzed using SPSS version 16 statistical package. All descriptive statistics were performed by univariate analysis. Bivariate analyses were also performed to identify crude predictors of household food insecurity, and finally, multivariable logistic regression was used to develop final model indicating the predictors of outcome variable.

Results: Based on the findings of this study, about 37.6\% households were food insecure. Of those households, 10.8\% were mildly food insecure, 23.2 and 3.6\% households were moderately and severely food insecure, respectively. Factors associated with household food insecurity were marital status (single household head) (AOR 4.06 at $95 \% \mathrm{Cl}$ 1.24, 13.27), greater than two dependent members (AOR 3.03 at 95\% Cl 1.38, 6.63), households headed with daily laborers (AOR 16.0 at 95\% Cl 4.57, 56.03), higher monthly income (AOR 0.013, at 95\% Cl 0.004, 0.05) and low monthly food expenditure (AOR 10.56 at $95 \% \mathrm{Cl} 2.61,42.71$ ) in the study area.

Conclusions: Household food insecurity was high in the study area compared to urban national level. Being single household head, having more than two dependent members in the household, daily laborers of household head and low monthly food outlay had statistically significant relationship with household food insecurity in negative direction. On the other hand, higher monthly income was significantly associated variable with household food insecurity in affirmative track. So, findings appoint as attention needed on stabilization of food markets, designing urban household food insecurity strategies and creating job opportunities to improve household food security in the setting.

Keywords: Associated factors, Household food insecurity, Household head, Wolaita Sodo town

\section{Background}

Adequate food in terms of quantity and quality for all people at all time is vital to a nation growth. Lack of

\footnotetext{
${ }^{*}$ Correspondence: yohannismulugeta@yahoo.com

${ }^{2}$ School of Public Health at Wolaita Sodo University (WSU), Wolaita Sodo, Ethiopia

Full list of author information is available at the end of the article
}

food in long terms leads to hunger and starvation [1]. Indicators of food security include availability of food, economic and physical access to food, adequate food utilization and sustainably having access to adequate food [2]. Food insecurity exists when all people, at all times, lack secure access to sufficient amounts of safe and nutritious food that meets their dietary needs and food preferences for an active and healthy life $[3,4]$. During food 
insecurity, people are not consuming enough food for an active and healthy life. This perhaps due to the unavailability of food, inadequate purchasing power or inappropriate utilization at household level [4].

Household food insecurity can be chronic and transitory in its type. Chronic food insecurity is often the result of extended periods of poverty, lack of assets and inadequate access to productive resources. Transitory household food insecurity is primarily caused by shortterm shocks and fluctuations in food availability and food access, including year-to-year variations in domestic food production, food prices and household income $[2,5]$. Ethiopia is a country that has a long history of household food security braves linked to rural households now facing new challenges related to urban setting $[6,7]$.

Household food insecurity is one of major public health problems in both developing and developed nations [4]. Based on Food and Agricultural Organization (FAO) report, 805 million (11.3\%) global populations were unable to meet their dietary energy supplies in 2012-2014. In developing countries, 791 million people live in hunger, which means $13.5 \%$ of the overall population remain tirelessly underfed [8]. Achieving food security for all people at all times remains a huge challenge for several developing countries. Ethiopia is one of the world poorest countries with needles suggesting low levels of progress, and it has been plagued with food insecurity for decades. Yet, food security appraisals in Ethiopia have traditionally focused on rural areas, and urban food security problems have got little attention [9].

According to the interim report of poverty analysis, the proportion of population below poverty line in urban area were $25.7 \%$, while the proportion of food poor people in urban area were estimated to be $28 \%$. That shows, over 1:4 Ethiopians fell below poverty line in urban settings [10]. Based on Household Consumption Expenditure (HCE) data of Ethiopia, at a national level, about half (49\%) of total household expenditures were on food for households. The level was higher in rural Ethiopia (51\%) than urban (41\%). Households who spend more than $65 \%$ of their expenditures on food are considered to have a high share of food expenditure [11]. Besides, studies done in different parts of Ethiopia revealed the main predictors of household food insecurity as: household incomes, occupation and educational status of household heads, household/family size, age of household head, access to credit, access to employment, proportion of expenditure on food and marital status of the household $[1,6,12]$.

Urbanization and/or urban migration resulted in alarming population pressure implying increased food demand. Food accessibility and affordability are considered to be the main factors for household food insecurity in urban setting. In addition, poverty, irregular household incomes, unemployment, dynamic and complex livelihoods are the root cause of urban household food insecurity. But, household food insecurity status at urban setting of Wolaita Sodo town was not inclusively studied. Therefore, this study was conducted at Wolaita Sodo town as benchmark to provide valuable information for stakeholders.

\section{Methods \\ Study setting}

The study was conducted in Wolaita Sodo town in Wolaita zone, Southwest Ethiopia. This locality is one of 13 zones in SNNPR located in southern part of the country at $385 \mathrm{~km}$ from Addis Ababa and $165 \mathrm{~km}$ southwest of the regional capital, Hawassa. Sodo Town is the capital city of Wolaita zone and located in $6^{\circ} 48^{\prime}-6^{\circ} 53^{\prime} \mathrm{N}$ latitude, $37^{\circ} 44^{\prime}-37^{\circ} 46^{\prime} \mathrm{E}$ longitude and at the altitude of 1500 $2500 \mathrm{~m}$. This town covers about $82.1 \mathrm{~km}^{2}$, and the total population is estimated to be 110,657 (57,477 males and 53,180 females). According to Wolaita Sodo town health office report, the total number of households in the town was seen as 22,584 in 2015. This settlement is structured in three sub-cities and 11 administrative kebeles. There are two hospitals, three health centers, 11 health posts and $>21$ private health institutions providing health services. Households produce their livelihood by civil services, non-government organizations employ, trading, small-scale industries, daily laborers, pension, etc.

\section{Study period, design and populations}

The study was conducted from August 6, 2015, to August 31, 2015, and a community-based cross-sectional study design was carried out. All household's head in Wolaita Sodo town and all randomly selected household heads in selected villages within the town were source and study populations. Besides, all household heads that were resident in Wolaita Sodo town for the past 6 months were included, and those who were not able to speak were excluded.

\section{Sample size determination and sampling procedures}

A single population proportion formula was used with the following assumptions: the level of urban food insecurity at Addis Ababa (58.2\%) [1], absolute precision (5\%), confidence limit (95\%) and design effect (1.5) for this study. Thus, the calculated sample size was 617 with eventuality for none response (10\%). Out of 11 kebeles in Wolaita Sodo town, five kebeles were selected by simple random sampling (SRS). Then, 15 villages were still selected by SRS from the list of 45 villages in selected five kebeles. Finally, to each village sample was allocated proportionally and households were selected by systematic random sampling method. 
Dependent variable Household food insecurity.

\section{Independent variables}

Sociodemographic factors Sex of household head, family size, age of household head, marital status of household head, educational status of household heads, ethnicity, religions, dependent members in households and occupation of household head.

Socioeconomic factors Monthly household incomes, access to credit, house ownership, and proportion of expenditure on food.

\section{Operational definitions}

Food insecurity Exists when all people, at all times, lack secure access to sufficient amounts of safe and nutritious food that meets their dietary needs and food preferences for an active and healthy life.

Mildly food insecure (access) household Worries about not having enough food sometimes or often and/or is unable to eat preferred foods.

Moderately food insecure household Sacrifices quality more frequently, by eating a monotonous diet or undesirable foods sometimes or often.

A severely food insecure household Experience forced cutting back on meal size or number of meals often, and/or experiences any of the three most severe conditions.

\section{Data collection method used for this study}

Data were collected using pretested and structured questionnaire. Household Food Insecurity Access Scale (HFIAS) developed by FANTA and validated for urban setting by Seifu Hagos at Butajira town was used [13]. Moreover, 12 food groups suggested by FANTA using a 24-h recall method were used to assess Household Dietary Diversity Score (HDDS) [13-15]. Questionnaire was initially prepared in English and translated to Amharic and finally back translated to English to check consistency and accuracy by language experts. Five diploma graduate nurses as data collector and two BSc public health professionals were recruited from Sodo town as supervisor based on their previous experience.

\section{Data quality assurance}

Enumerators and supervisors were trained for 2 days, 1 week prior to date of data collection on: study objectives, key highlights in methods to assess household food insecurity, data collection and interviewing approach, and data recording. Pretesting was done on 5\% (31 households) of the sample from two kebeles, which were not selected for actual study. Data collection was strictly supervised in daily basis. Data were then checked for completeness and consistency before data entry. Data were entered in Epi Info version 3.5.3. Then, data were exported to SPSS version 16 for further data processing and/or analysis.

\section{Data processing and analysis}

Households were classified based on responses to the nine severity items in the HFIAS and coded "0" for "No" and " 1 " for "Yes." The procedure for scoring was used as follows: "0" was attributed if the event described by the question never occurred, " 1 " if it occurred during the previous 30 days. With regard to the occurrence, "1" was attributed if the events rarely occur, " 2 " sometimes and " 3 " often. Therefore, responses on the nine HFIAS questions were summed using the SPSS 16 program to create household food security score, with a minimum of " 0 " and a maximum score of "27." According to the score, the higher the score, the more the household is vulnerable to food insecurity. The lower the score, the lesser the food insecurity a household experienced. Therefore, HFIAS score of $0-1$ is categorized as food secure, 2 and above were considered as food insecure. Households scored $2-7,8-14$ and $15-27$ were categorized to be mildly, moderately and severely food insecure households, respectively.

Descriptive statistics like frequencies, proportions, mean, graph and table were used to present study results. Bivariate and multivariable logistic regressions were computed to assess the association between the study variables and to control possible confounders. All variables with $P$ value $\leq 0.25$ were selected as candidate for multivariable analysis. $P$ value $<0.05$ was used as yardstick to judge the association as statistically significant. Both crude (OR) and adjusted odds ratio (AOR) with 95\% confidence interval were reported to show the strength of association between study variables.

\section{Results}

\section{Sociodemographic and socioeconomic characteristics of households}

A total of 609 households participated in this study with the response rate of $98.7 \%$. The mean (SD) age of household head was 43.03 (9.77) years, and 488 (80.1\%) household heads included were males. Larger segment of participants 479 (78.7\%) was married, and about 402 (66\%) households have 4-6 family members. Besides, households with $\leq 2$ dependent members were 422 (69.3\%), and household heads attended formal education were 425 (69.8\%). In terms of livelihood, among household heads included, 321 (52.7\%) were self-employed and 308 (50.6\%) gain monthly income of $>1901 \mathrm{ETB} / 87$ USD. The extent of households reporting ownership of assets can be described for mobile phone 536 (88\%), TV/DVD/ Radio 485 (79.6\%) and modern bed 402 (66.0\%) from principally available assets. Few households reported 
possession of the following wealth: car 9 (1.5\%), bicycle 54 (8.9\%), refrigerator 149 (24.5\%), jeweler 191 (31.4\%), sofa set $219(36.0 \%)$ of the participants (Table 1$)$.

\section{Access to food and food consumption in Wolaita Sodo town, 2015}

All households included in this study purchase their food primarily from market. Almost half of households used $\geq 1201 \mathrm{ETB} / 55$ USD for food expenses, and 124 (20\%) of the households reported eating $\leq 2$ meals per day. Majority of the households $582(95.6 \%)$ consumed cereals as their staple food over $24 \mathrm{~h}$ prior to this survey. Additionally, 557 (91.5\%) households consumed vegetables, 482 (79.1\%) oils or fats, 587 (96.4\%) miscellaneous (tea and coffee), 455 (74.7\%) sugar or honey, 401 (65.8\%) pulses, 331 (54.4\%) roots or tubers, 9 (1.5\%) fish, 42 (6.9\%) meat,

Table 1 Sociodemographic characteristics of the respondents in Sodo town, 2015

\begin{tabular}{|c|c|c|c|}
\hline Variable $N=609$ & Category & Frequency & $\%$ \\
\hline \multirow[t]{2}{*}{ Sex of HH head } & Male & 488 & 80.1 \\
\hline & Female & 121 & 19.9 \\
\hline \multirow[t]{3}{*}{ Age of HH head } & $20-40$ & 286 & 47.0 \\
\hline & $41-64$ & 287 & 47.1 \\
\hline & 65 and above & 36 & 5.9 \\
\hline \multirow[t]{3}{*}{ Family size } & $1-3$ & 66 & 10.8 \\
\hline & $4-6$ & 402 & 66.0 \\
\hline & 7 and above & 141 & 23.2 \\
\hline \multirow[t]{3}{*}{ Religion } & Orthodox & 295 & 48.4 \\
\hline & Protestant & 274 & 45.0 \\
\hline & Others & 40 & 6.6 \\
\hline \multirow[t]{5}{*}{ Ethnicity } & Wolaita & 411 & 67.5 \\
\hline & Amhara & 66 & 10.8 \\
\hline & Gurage & 47 & 7.7 \\
\hline & Gamo & 64 & 10.5 \\
\hline & Others & 21 & 3.5 \\
\hline \multirow[t]{5}{*}{ Marital status of HH head } & Married & 479 & 78.7 \\
\hline & Unmarried & 6 & 1.0 \\
\hline & Divorced & 26 & 4.3 \\
\hline & Separated & 13 & 2.0 \\
\hline & Widowed & 85 & 14.0 \\
\hline \multirow[t]{2}{*}{ Educational status } & No formal education & 184 & 30.2 \\
\hline & Formal education & 425 & 69.8 \\
\hline \multirow[t]{4}{*}{ Occupation of HH head } & Self-employed & 321 & 52.7 \\
\hline & GOV/NGO employed & 120 & 19.7 \\
\hline & Daily wage & 115 & 18.9 \\
\hline & Pension & 53 & 8.7 \\
\hline \multirow[t]{3}{*}{ Monthly income } & $\leq 1000$ & 184 & 30.2 \\
\hline & $1001-1900$ & 117 & 19.2 \\
\hline & $\geq 1901$ & 308 & 50.6 \\
\hline
\end{tabular}

82 (13.5\%) egg, 169 (27.8\%) fruits and 176 (28.9\%) milk and milk products over $24 \mathrm{~h}$ prior to the survey.

\section{Household Dietary Diversity Score and prevalence} of household food insecurity in the study area

The mean (SD) dietary diversity score of households was found as $6.36( \pm 1.36)$, and households were labeled to three groups by using this mean score. Over 160 (26.3\%) households were located at poorly diverse dietary consumers (who consume $\leq 5$ food groups), 288 (47.3\%) households at medium dietary diversity (who consume 6-7 food groups) and $26.4 \%$ of households are classified in betterly diverse dietary consumers (who consume $>7$ food groups) accordingly. Among the participants, 229 (37.6\%) responded affirmatively to the nine occurrence questions, labeling them as food insecure households. Based on set cutoff points, 66 (10.8\%) households classified as mildly food insecure. Households classified as moderately and severely food insecure were 141 (23.2\%) and 22 (3.6\%), respectively (Fig. 1).

The study finding reveals as 227 (37.3\%) households worried food inaccessibility and 229 (37.6\%) households were not able to eat the kinds of food they preferred due to lack of resources. Moreover, about 226 (37.1\%) households reported that they did not consume a variety of food they prefer, $173(28.4 \%)$ ate unwanted food, 200 $(32.8 \%)$ ate small amount meal and $168(27.6 \%)$ ate few meals per day. The proportion of households who experienced lack of food to eat was 44 (7.2\%) and going to bed without eating were 25 (4.1\%) based on the findings of this study (Table 2).

\section{Domains of household food insecurity in Wolaita Sodo town}

The nine occurrence items can further be summarized into three major domains: (I) feelings of uncertainty or anxiety about the household food supplies (represented by item 1), (II) perceptions that household food is of

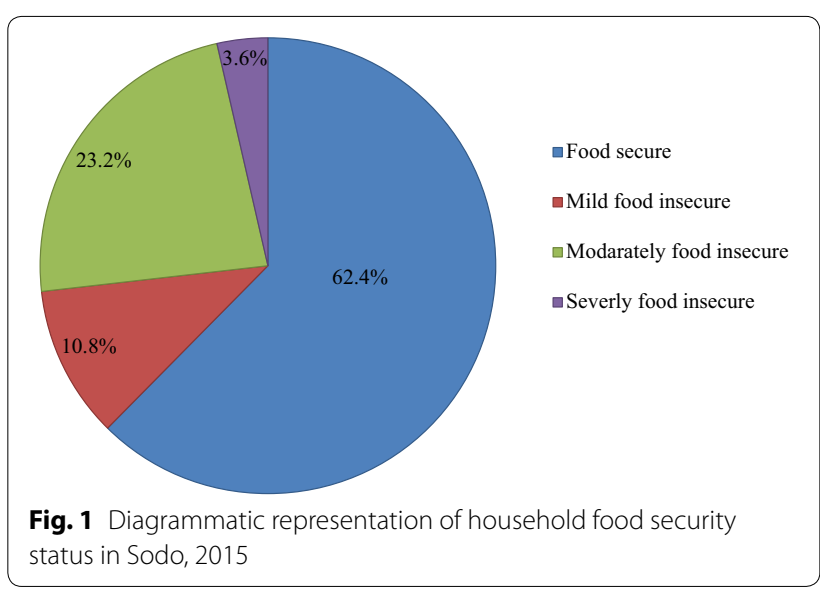


Table 2 Occurrence of HFIAS conditions in Sodo town, 2015

\begin{tabular}{lll}
\hline Indicator & No & Total (yes) \\
& N (\%) & N (\%) \\
\hline Worry about not having enough food? & $382(62.7)$ & $227(37.3)$ \\
Unable to eat preferred food & $380(62.4)$ & $229(37.6)$ \\
Eat just a few kinds of food & $383(62.9)$ & $226(37.1)$ \\
Eat food really do not want & $436(71.6)$ & $173(28.4)$ \\
Eat smaller amounts in meal & $409(67.2)$ & $200(32.8)$ \\
Eat fewer meals in a day & $441(72.4)$ & $168(27.6)$ \\
No food of any kind in household & $565(92.8)$ & $44(7.2)$ \\
Go to sleep hungry at night & $584(95.9)$ & $25(4.1)$ \\
Go a whole day and night without food & $604(99.2)$ & $5(0.8)$ \\
\hline
\end{tabular}

insufficient quality and food type preference (signified by items 2-4), and (III) insufficient food intake and its physical consequences (items 5-9). The computed percentage for anxiety and uncertainty domains was 227 (37.3\%), for the insufficient food quality domain 229 (37.6\%) and insufficient food intake and its physical costs domain was 202 (33.3\%) in the study area (Fig. 2).

\section{Factors associated with household food insecurity in Wolaita Sodo town}

The candidate variables selected for multivariable logistic regression were: sex of household head, age of household head, family size, marital status, dependent member, occupation, monthly income, food expenditure, house ownership and credit access. Variables retained their statistical significance in multivariable model were: marital status, dependent member in household, occupation, monthly income of household and monthly food

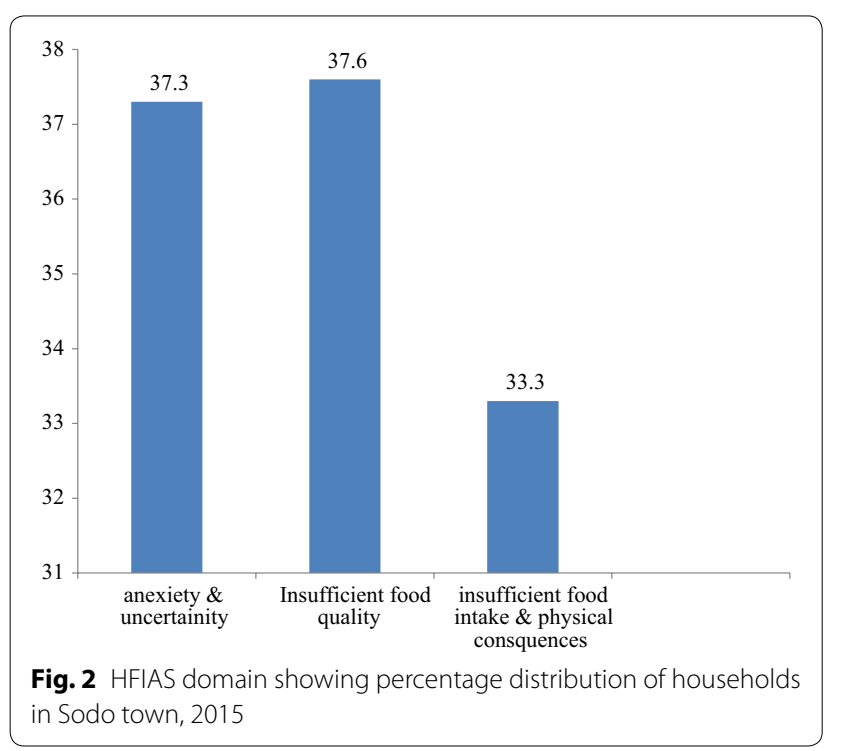

expenditure. Households headed with single (unmarried, separate, divorced and widowed) were 4.0 times more likely to be food insecure compared with married (AOR 4.06 at $95 \%$ CI $1.24,13.27)$. Households with $>2$ dependent members were 3.0 times (AOR 3.03 at 95\% CI 1.38, 6.63) more likely to be food insecure than $\leq 2$ dependent member in households. Household heads who were daily laborers were 16 times (AOR 16.0 at 95\% CI 4.57, 56.03) more likely to be food insecure when compared with selfemployed. The results also show that households gaining higher monthly income (>1901 ETB) were 98.7\% (AOR 0.013 at $95 \%$ CI $0.003,0.051$ ) less likely to be food insecure compared to lower monthly income (<1000 ETB). Households expending $\leq 700$ ETB for monthly food utilization were 10.5 times (AOR 10.56, 95\% CI 2.61, 42.71) more likely to be food insecure than with households who expend $\geq 1201$ EB (Table 3 ).

\section{Discussion}

This study looked at the level and associated factors of household food insecurity in an urban area of Sodo town using validated HFIAS. A total of $37.6 \%$ households were food insecure (10.8, 23.2 and 3.6, mildly, moderately and severely food insecure, respectively). The study showed that single household head, dependent member in household, daily laborer household head, monthly income and monthly food expenses were significant predictors of household food insecurity in the study area.

The state of household food insecurity (37.6\%) identified in this study was analogous with studies done in Shashemene (36\%), Kenya (38\%) and national report (35\%) [16-19]. However, it was lower than findings reported by studies conducted in South Delhi and Malda district of India (77.2 and 68.38\%), Kinshasa (70\%), Addis Ababa city (75 and 58.2\%), Dire Dawa town (43\%), Farta district (70.7\%), Manna district (42.9\%), Offa district (57\%) and Boloso Sore district (65.5\%) [1, 4, 6, 12, 20-26]. The possible reason to variation might be the coincidence of the data collection with a harvest season, where food is more available and the prices are relatively low. Thus, lower household food insecurity in this study might be associated with harvesting season of the year where the study was performed. In contrary, the finding observed in this study tends to be higher than the findings of some studies such as Pakistan (19\%), Humbo (28.4\%) and urban areas of Ethiopia (28.0\%) [10, 27-29]. The disparity might be due to the agroecological differences in settings and socioeconomic variations among study areas.

The finding expressed as single household heads were 4 times more likely to be food insecure than married households was similar to findings of studies done in South Africa and Dire Dawa [12, 30]. This might be owing to less family income and low purchasing power. 
Table 3 Bivariate and multivariable analysis on factors associated with household food insecurity

\begin{tabular}{llll}
\hline $\begin{array}{lll}\text { Variable } \\
(n=609)\end{array}$ & $\begin{array}{l}\text { Food security } \\
\text { status }\end{array}$ & \\
\cline { 2 - 2 } & Insecure Secure & & \\
& &
\end{tabular}

Sex of $\mathrm{HH}$

Female

Male

Age of $\mathrm{HH}$

20-40

41-64

65 and above $\quad 26$

Family size

$1-3$

4,6

7 and above

Marital status

Singles

Married

Dependent

$>2$ members

$\leq 2$ members

Occupation

Pension

Daily wage $\quad 108$

Gov/NGO 21

employed

Self-employed

Education

No formal education

Formal educa- 127

tion

Monthly

income

$\leq 1000$ birr $\quad 169$

1001 ,

1900 birr

$\geq 1901$ birr

49$$
11
$$

11

Food expendi-

ture

$$
\leq 700
$$$$
\text { 701-1200 }
$$

$$
\geq 1201
$$

House owner-

ship

$\begin{array}{lrlll}\text { Rent house } & 150 & 115 & 4.38(3.09,6.21) & 1.04(0.48,2.23) \\ \text { Private owner } & 79 & 265 & 1 & 1\end{array}$

$P$ value $<0.05^{*}$ significantly associated, $P$ value $<0.01^{* *}$ strongly statistically significant
Moreover, households with $>2$ dependent members were 3 times more likely to be food insecure than households with $\leq 2$ dependent members. The higher the number of dependents in the household, the lower the income generated to purchase food items to fulfill all family needs. Thus, a lower household income and increased family size tend to worsen household food insecurity. The findings from related studies done in Zimbabwe, Humbo and Sodo town agree with this finding [19, 27, 31, 32]. The study also revealed as daily laborers were 16 times more likely to be food insecure compared to self-employed. This may be due to low income, social security and purchasing power of the daily laborers. Pensions were also the most affected because their income was small and experience higher food prices. However, self-employed were able to toil multiple works and compensate partly the high food prices. It was comparable with study conducted in Addis Ababa, Bangladesh and India [6, 21, 33].

Households who reported higher monthly income were less likely to be food insecure than relatively smaller income gainers. Researches done in South Africa, Addis Ababa city and Dire Dawa also shown that households with higher monthly income were less likely to suffer from household food insecurity than households with lower incomes $[6,12,30]$. Regarding to food expenditure, households expending $\leq 700$ ETB for monthly food purchase were 11 times more likely to be food insecure than those households who expend more. The finding was like studies done in North India and Dire Dawa [12, 21]. This could be due to low income accompanied with low purchasing power. As the proportion of expenses on food decline and access to food by household also decrease, this may end up with shortage of food variety as well as quantity.

\section{Limitations of the study}

Data collection concerns by HFIAS (relies on the recall of events occurred in the last four weeks). Concurrence of study period with harvest season might underestimate the situation of household food insecurity in the setting. Besides, issues related to monthly income of household and expenditure (relies on report from household head) were the possible limitations of this study.

\section{Conclusions}

The study concludes as household food insecurity is not only a rural issue but also substantial in urban settings. The findings shown as higher extent of households were food insecure in the study area than national description for similar setting (urban setting). Furthermore, single headed households, dependent members in households, daily laborer household head, higher monthly income 
and low food expenditure were significant predictors of household food insecurity. Municipality, health and agriculture sector, and other stakeholders need to take action toward improving household food security state in the study area. Actions should focus on: strengthening micro-finance and small business enterprise to increase access to food via amplified income, design strategies on household food security program [e.g., Productive Safety Net Program (PSNP)]; strengthening family planning methods, stabilization of food markets/prices and income generating activities should be encouraged. Besides, backup of saving practice to ensure resilience for food insecure households is also needed. Further studies are desirable to come across seasonal variations of household food insecurity in urban setting.

\section{Abbreviations}

AOR: adjusted odds ratio; FANTA: Food and Nutrition Technical Assistance; HFIAS: Household Food Insecurity Access Scale; HDDS: Household Dietary Diversity Score; NORAD: Norwegian Agency for Development; SENUPH: South Ethiopian Network of Universities in Public Health.

\section{Authors' contributions}

AT monitored data collection and involved in analysis and report writing grossly; TD reviewed study design and data analysis and contributed in report write-up; BK reviewed data analysis and contributed in report write-up; MY* had decisive scientific role in design, analysis, interpretation of findings and write-up. All authors read and approved the final manuscript.

\section{Authors' information}

AT is graduate of MSc degree in human nutrition from Wolaita Sodo University (WSU) and currently acting as zonal coordinator of Targeted Supplementary Feeding Program (TSFP) at Southern Ethiopia. TD is Ph.D. holder and associate professor of human nutrition. He is one of senior nutritionists in the country and acting as consultant nutritionist and academician at Wolaita Sodo University (WSU). BK is senior researcher with Ph.D. and published large number of journals in reputable journals. Currently, he is linked with College of agriculture at Wolaita Sodo University. MY is a nutrition specialist and statistician. He published highly readable articles in nutrition and public health field. He is young and successful researcher, presently coordinating Ph.D. project focused in food and nutrition in vulnerable groups.

\section{Author details}

${ }^{1}$ Targeted Supplementary Feeding Program (TSFP), Wolaita Sodo, Southern Ethiopia, Ethiopia. ${ }^{2}$ School of Public Health at Wolaita Sodo University (WSU), Wolaita Sodo, Ethiopia. ${ }^{3}$ College of Agriculture at Wolaita Sodo University (WSU), Wolaita Sodo, Ethiopia. ${ }^{4}$ Damot Pulasa District, Wolaita Zone, Wolaita Sodo, Southern Ethiopia, Ethiopia.

\section{Acknowledgements}

Authors thank "South Ethiopia Network of Universities in Public health" project (SENUPH) under the "Norwegian Agency for Development (NORAD)" for supporting the project. This study would have been not viable lacking hosting and facilitation of the school of public health in Wolaita Sodo University. Deepest thanks go to authorities of Wolaita Sodo town administrations for their cohesion. Besides, authors are highly indebted to data collectors and respondents, because their integrity has leading value on the findings of this study.

Exchange rate from ETB to USD differs from time to time. However, it was IUSD: 22.40 ETB (One USD is equal to 22.40 ETB) at the time of data collection.

\section{Competing interests}

The authors declare that they have no competing interests.

\section{Availability of data and materials}

The datasets analyzed during the current study were available from the corresponding author on reasonable request.

\section{Ethics approval and consent to participate}

Ethical clearance was obtained from the ethical review committee of college of health sciences and medicine, Wolaita Sodo University. Then, concerned officials in Wolaita Sodo town at each level were communicated through formal official letters from the school of public health. The town health office provided official letter to local authorities of all selected kebeles. Informed verbal consent was obtained from each participant before interview. To ensure confidentiality of participants, anonymous coding was used whereby the name of the participants and any participants'identifier were not written on the survey note. Even during the interview time, to keep the privacy of subject's interview was carried out at private place and alone (only interviewer and respondent listens each other). Moreover, the rights of members not to take part and not to answer the query they don't want to answer were ensured.

\section{Funding}

This research was supported by NORAD_SENUPH project.

Received: 29 October 2016 Accepted: 17 February 2017

Published online: 27 February 2017

\section{References}

1. Gebre GG. Dimensions of Urban Food Insecurity: the Case of Addis Ababa, Ethiopia. J Agric Econ Rural Dev. 2014;2(1):1-9.

2. Food Security Concepts and Frameworks, in EC-FAO Food Security Information for Action Programme. 2008, FAO.

3. Bryceson DF. Nutrition and the commoditization of food in sub-Saharan Africa. Soc Sci Med. 1989;28(5):425-40

4. Worku Endale ZBM, Azeb A, Akilew AA. Food Insecurity in Farta District, Northwest Ethiopia: a community based cross-sectional study. BMC Res Notes. 2014;7:130

5. Mustaquim MIDM. Food Insecurity and Indian Muslims. IOSR J Humanit Soc Sci. 2013;11(1):121-6.

6. Sadler K. Community-based therapeutic care: treating severe acute malnutrition in sub-Saharan Africa. London: University College London; 2010.

7. Kaluski DN, Ophir E, Amede T. Food security and nutrition, the Ethiopian case for action. Public Health Nutr. 2002;5(3):373-81.

8. MOH. Training course on the management of severe acute malnutrition. In: Addis Ababa, Ethiopia; 2013.

9. Alem H:Transitory food insecurity and Coping strategies in north western Ethiopia. In: Sixth international conference in agricultural statistics 2013.

10. Ethiopia's Progress Towards Eradicating Poverty. An Interim Report on Poverty Analysis Study (2010/11). Addis Ababa: Development Planning and Research Directorate Ministry of Finance and Economic Development; 2012

11. Ethiopia Comprehensive Food Security and Vulnerability Analysis (CFSVA) (Central Statistical Agency and WFP Ethiopia report). March 2014

12. Feleke A, Bogale A. Determinants and Dimensions of Household Food Insecurity in Dire Dawa Town, Ethiopia. E Afr J Sci. 2009;3(2):134-41.

13. Gebreyesus SH, Lunde T, Mariam DH, Woldehanna T, Lindtjørn B. Is the adapted Household Food Insecurity Access Scale (HFIAS) developed internationally to measure food insecurity valid in urban and rural households of Ethiopia? BMC Nutr. 2015:1 (2):2-10

14. Jennifer Coates AS, Paula Bilinsky. Household Food Insecurity Access Scale (HFIAS) for measurement of food access: Indicator Guide, Version 3. August 2007.

15. Swindale A, Bilinsky P: Household Dietary Diversity Score (HDDS) for measurement of household food access: indicator guide FANTA III. September 2006; 2 .

16. Kaloi B, Tayebwa B, Bashaasha B. Food security status of households in Mwingi District, Kenya. Afr Crop Sci Conf Proc. 2005;7:867-73.

17. Mitiku A, Fufa B, Tadese B. Empirical analysis of the determinants of rural households food security in Southern Ethiopia: The case of Shashemene District. Basic Res J Agric Sci Rev. 2012;6(1):132-9. 
18. Belachew T, Hadley C, Lindstrom D, Gebremariam A, Michael KW, Getachew Y, Lachat C, Kolsteren P. Gender differences in food insecurity and morbidity among adolescents in southwest Ethiopia. Pediatrics. 2011;127(2):e398-405

19. Abo T, Kuma B. Determinants of food security status of female-headed households: the case of Wolaita Sodo town, South Nations, Nationalities and Peoples Region, Ethiopia. Int J Sci Foot Prints. 2015;3(2):8-24.

20. Bogale Gebeyehu GR, Tebeje M. Rural households food security and livelihood strategies: the case of Offa woreda, in wolaita Sodo Zuria, Southern Nation, Nationalities and Peoples Regional State, Ethiopia. IJRESS. 2014:4(7)91-104

21. Chinnakali P, Upadhyay RP, Shokeen D, Singh K, Kaur M, Arvind K, Singh A, Goswami A, Yadav K, Pandav CS. Prevalence of household-level food insecurity and its determinants in an Urban Resettlement Colony in North India. J Health Popul Nutr. 2014;32(2):227-36.

22. Ismail M. Status of food security in some selected villages in Malda District. Soc Sci. 2012; 2:64-87

23. Lebailly P, Muteba Kalala D. Characteristics of Urban Food insecurity: the case of Kinshasa. Afr Rev Econ Financ. 2011;3(1):58-68

24. Leza T, Kuma B. Determinants of rural farm household food security in Boloso Sore District of Wolaita Zone in Ethiopia. Asian J Agric Ext Econ Sociol. 2015;5(2):57-68.
25. Mequnent Muche BETK. Determinants of household food security among Southwest Ethiopia rural households. Asian J Agric Res. 2014;8(5):248-58.

26. Ismail M, Mustaquim DM. Food Insecurity and Indian Muslims. IOSR J Humanit Soc Sci. 2013;11(1):121-6.

27. Guja MM. Household food security status and coping strategies in Humbo Wereda, SNNPR, Ethiopia. Int J Sci Basic Appl Res. 2012;6(6):77.

28. Bashirab MK, Schilizzi S, Pandita R. Livestock and rural household food security: the case of small farmers of the Punjab, Pakistan working paper 1207. School of Agricultural and Resource Economics, University of Western Australia, Crawley, Australia; 2012

29. Shone M, Demissie T, Yohannes B, Yohannis M. Household food insecurity and associated factors in West Abaya district, Southern Ethiopia, 2015. Agric Food Secur. 2017;6(2):1-9.

30. Ndobo F. Determinants of vulnerability to food insecurity in a South African Township: a gender analysis. Mediterr J Soc Sci. 2013:4(14):311-317

31. Tawodzera G. Vulnerability in crisis: urban household food insecurity in Epworth, Harare, Zimbabwe. Food Sec. 2011:3:503-20.

32. Eneyew A, Bekele W. Causes of household food insecurity in Wolaita: Southern Ethiopia. J Stored Prod Postharvest Res. 2012;3(3):35-48.

33. Faridi R. An econometric assessment of household food security in Bangladesh. Bangladesh Dev Stud. 2010;98-111.

\section{Submit your next manuscript to BioMed Central and we will help you at every step:}

- We accept pre-submission inquiries

- Our selector tool helps you to find the most relevant journal

- We provide round the clock customer support

- Convenient online submission

- Thorough peer review

- Inclusion in PubMed and all major indexing services

- Maximum visibility for your research

Submit your manuscript at www.biomedcentral.com/submit 